\title{
Questionnaire-Based Survey on Epidemiology of Functional Gastrointestinal Disorders and Current Status of Gastrointestinal Motility Testing in Asian Countries
}

\author{
Takeshi Kamiya $^{a}$ Satoshi Osaga ${ }^{a}$ Eiji Kubota $^{b}$ Shin Fukudo ${ }^{c}$ Satoshi Motoyad \\ Kazunari Murakami ${ }^{e}$ Akihito Nagahara ${ }^{f}$ Akiko Shiotani $^{g}$ Mitsushige Sugimoto $^{\text {h }}$ \\ Hidekazu Suzuki ${ }^{i}$ Toshio Watanabe $^{j}$ Satoru Yamaguchi ${ }^{k}$ Francis K.L. Chan' \\ Ki-Baik Hahm ${ }^{\mathrm{m}}$ Kwong Ming Fock ${ }^{\mathrm{n}}$ Qi Zhu ${ }^{\circ}$ The International Gastroenterology \\ Consensus Symposium Study Group
}

\begin{abstract}
aDepartment of Medical Innovation, Nagoya City University Graduate School of Medical Sciences, Nagoya, Japan; bDepartment of Gastroenterology and Metabolism, Nagoya City University Graduate School of Medical Sciences, Nagoya, Japan; 'Department of Behavioral Medicine, Tohoku University Graduate School of Medicine, Sendai, Japan; ' IIBD Center, Sapporo Kosei General Hospital, Sapporo, Japan; ${ }^{e}$ Faculty of Medicine, Oita University, Oita, Japan; fDepartment of Gastroenterology, Juntendo University School of Medicine, Tokyo, Japan; ${ }^{\text {DDivision }}$ of Gastroenterology, Department of Internal Medicine, Kawasaki Medical School, Okayama, Japan; hepartment of Gastroenterological Endoscopy, Tokyo Medical University Hospital and Hepatology, Tokyo, Japan; 'Division of Gastroenterology and Hepatology, Department of Internal Medicine, Tokai University School of Medicine, Isehara, Japan; 'Department of Gastroenterology, Osaka City University Graduate School of Medicine, Osaka, Japan; kFirst Department of Surgery, Dokkyo Medical University, Tochigi, Japan; 'Department of Medicine \& Therapeutics, The Chinese University of Hong Kong, Hong Kong, Hong Kong SAR; mDigestive Disease Center, CHA University School of Medicine and CHA University Bundang Medical Center, Seoul, South Korea; 'Department of Gastroenterology, Changi General Hospital, Singapore, Singapore, Singapore; ${ }^{\circ}$ SinoUnited Health, Ruijin Hospital, Shanghai Jiaotong University School of Medicine, Shanghai, China
\end{abstract}

\section{Keywords}

Constipation - Colonic motility · Functional dyspepsia .

Gastric emptying · Gastroparesis · Irritable bowel syndrome

\begin{abstract}
Background/Aims: Functional gastrointestinal disorders (FGIDs) are diagnosed and classified using the latest Rome IV criteria, released in 2016. Epidemiology of FGID diagnosed by the Rome IV criteria and current clinical application of
\end{abstract}

gastrointestinal motility testing in Asian countries are not well known. The aims of this survey are to elucidate the present situation of epidemiology and diagnostic tests of FGID in clinical practice in some East and Southeast Asian countries. Methods: The questionnaire focusing on current situation of FGID diagnosis and gastrointestinal motility testing was distributed to members of the International Gastroenterology Consensus Symposium study group and collected to be analyzed. Results: The prevalence rates of subtypes of both functional dyspepsia (FD) and irritable bowel syndrome (IBS)

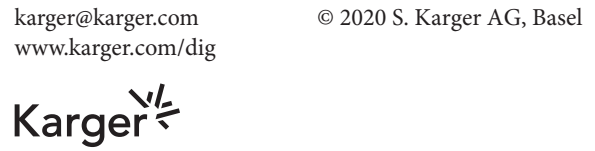


are relatively similar in all Asian countries. In these countries, most patients underwent both upper endoscopy and Helicobacter pylori test to diagnose FD. Colonoscopy was also frequently performed to diagnose IBS and chronic constipation. The frequency of gastrointestinal motility testing to examine gastric emptying and colonic transit time varied among Asian countries. Conclusions: This survey revealed epidemiology of FGIDs and current status of gastrointestinal motility testing in some East and Southeast Asian countries.

๑) 2020 S. Karger AG, Basel

\section{Introduction}

Functional gastrointestinal disorders (FGIDs) are a group of gastrointestinal disorders defined by specific symptoms and absence of structural or chemical abnormalities that cause these symptoms [1]. FGIDs consist of several different diseases including functional dyspepsia (FD) [2] and irritable bowel syndrome (IBS) [3], which are very common in clinical setting. The gastrointestinal symptoms may represent any combination of symptoms, such as impaired gastrointestinal motility $[4,5]$, visceral hypersensitivity $[4,6]$, gut microbiota $[7,8]$, altered mucosal function [7], and/or central nervous system processing [4, 9]. The Rome IV criteria [1], released in 2016, have been widely used to diagnose and classify FGIDs worldwide. Furthermore, several gastrointestinal motility tests have been performed as diagnostic methods of FGID especially in Western countries. However, the epidemiology of FGID diagnosed by the Rome IV criteria is unknown and clinical application of gastrointestinal motility testing is not established in Asian countries. In this survey, we aim to elucidate present situation of epidemiology and diagnostic tests of FGID in clinical practice using the questionnaire in some East and Southeast Asian countries.

\section{Methods}

\section{Participant}

This survey was conducted by the International Gastrointestinal Consensus Symposium (IGICS). Representatives of China, Indonesia, Hong Kong, Japan, Korea, Philippines, Singapore, and Thailand were selected from IGICS committee, and the committee sent them a questionnaire on epidemiology of FGID based on the Rome IV criteria and functional GI motility testing in clinical practice. The definition of FGID was based on Rome IV criteria to select the more homogenous subset from various patients. A representative distributed this questionnaire to major institutions including universities, hospitals, and clinics in each country, starting at the beginning of October 2019. Responses from institutes were collected by the end of November 2019. The questionnaire consisted of 23 questions focusing on the following: (1) background of respondents and institutes; (2) epidemiology and diagnostic tools of FD, gastroparesis (GP), IBS, and chronic constipation (CC) in each institution; (3) current situation of several GI motility testing including gastric emptying (GE) and colonic transit time. The details of the questionnaire are described in Appendix.

\section{Statistical Analysis}

The data were expressed as mean or median as appropriate. The percentages of FD, GP, IBS, and CC cases were obtained by dividing the number of the cases by persons who visited the institutes per month. When an answer to a question had a certain range, mean value was used (e.g., if a respondent wrote " $5-10$," we used "7.5" as the answer to the item). The significance of differences among above 8 countries was assessed with the KruskalWallis test or $\chi^{2}$ test as appropriate. $p$ value $<0.05$ was considered to be statistically significant.

Table 1. Background of the respondents

\begin{tabular}{|c|c|c|c|c|c|c|c|}
\hline \multirow[t]{2}{*}{ Country } & \multirow{2}{*}{$\begin{array}{l}\text { Number of } \\
\text { institutes* }\end{array}$} & \multicolumn{2}{|c|}{ Patients numbers/month } & \multicolumn{4}{|l|}{ Specialty } \\
\hline & & average & (range) & gastroenterology & surgery & $\begin{array}{l}\text { general } \\
\text { physician }\end{array}$ & others \\
\hline China & 21 & 10,100 & $(200-40,000)$ & 21 & 0 & 0 & 0 \\
\hline Hong Kong & 19 & 2,800 & $(250-18,000)$ & 17 & 0 & 2 & 0 \\
\hline Indonesia & 10 & 1,600 & $(100-7,000)$ & 5 & 1 & 2 & 2 \\
\hline Japan & 72 & 1,500 & $(50-7,300)$ & 66 & 2 & 4 & 0 \\
\hline Korea & 24 & 15,000 & $(280-250,000)$ & 24 & 0 & 0 & 0 \\
\hline Philippines & 28 & 500 & $(20-2,000)$ & 28 & 0 & 0 & 0 \\
\hline Singapore & 4 & 1,200 & $(500-2,000)$ & 4 & 0 & 0 & 0 \\
\hline Thailand & 18 & 1,300 & $(80-10,000)$ & 18 & 0 & 0 & 0 \\
\hline All countries & 196 & & & 181 & 3 & 8 & 2 \\
\hline
\end{tabular}

* There was one respondent from each institute. 


\section{Results}

\section{Background of Respondents and Institutes}

A total of 196 respondents who were employed at 196 institutes returned the questionnaire. The number of institutes participating in this survey was 72 in Japan and 124 in China, Indonesia, Hong Kong, Korea, Philippines, Singapore, or Thailand. With regard to their specialty, the respondents of each institute were mostly gastroenterologists, and the remaining respondents were surgeons, general physicians, or others (Table 1).
Prevalence of FGIDs

Functional Dyspepsia

The median percentage of patients who were diagnosed as FD defined by the Rome IV criteria among patients who visited the respondent's institution was 10.0, $15.0,8.3,3.3,11.2,20.0,8.8$, or $4.5 \%$ in China, Hong Kong, Indonesia, Japan, Korea, Philippines, Singapore, and Thailand, respectively, showing significant differences between countries (Fig. 1).

Figure 2 shows prevalence of subtypes of FD using the Rome IV criteria in each country. Epigastric pain syndrome (EPS) was more prevalent than postprandial distress syndrome (PDS) in Hong Kong, Indonesia, Korea,

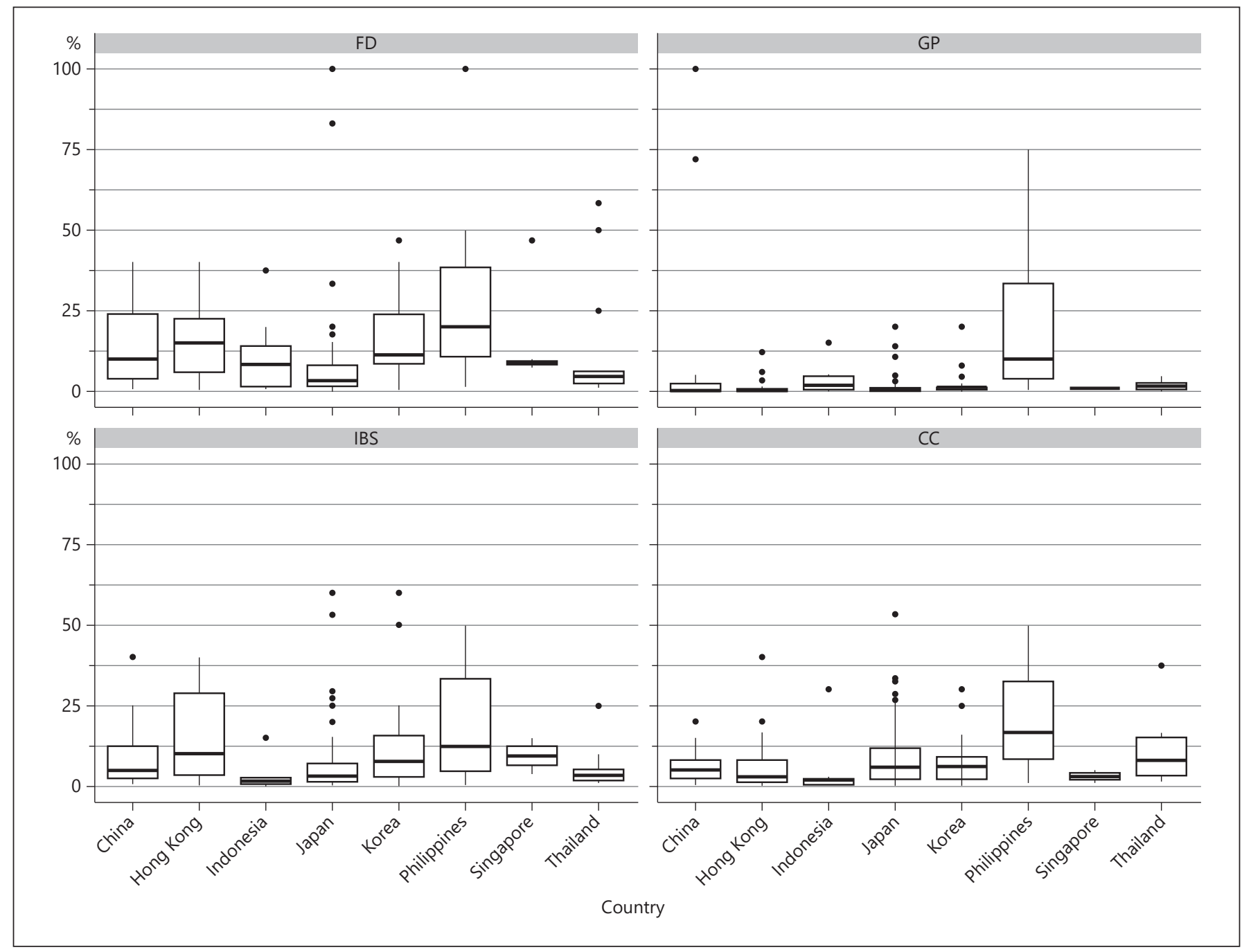

Fig. 1. Percentage of patients who were diagnosed as FD, GP, IBS, or CC among patients who visited each institution. Box plots indicate the median. spots indicate outliers. There were significant differences between countries ( $p<0.001$, Kruskal-Wallis test). FD, functional dyspepsia; GP, gastroparesis; IBS, irritable bowel syndrome; CC, chronic constipation. 


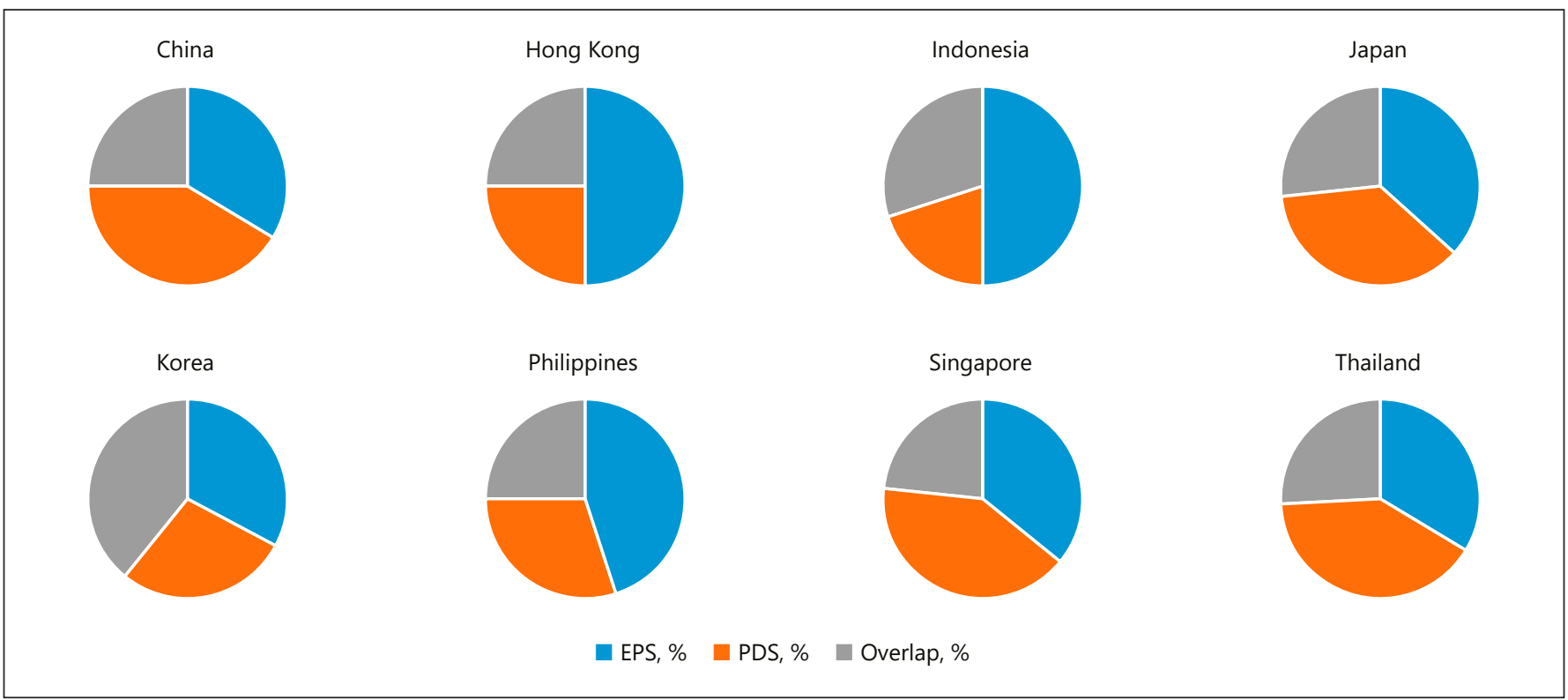

Fig. 2. Prevalence of subtypes of FD in each country. FD, functional dyspepsia; EPS, epigastric pain syndrome; PDS, postprandial distress syndrome; Overlap, overlap of EPS and PDS.

Table 2. The most important factors to diagnose GP as rated by respondents

\begin{tabular}{lllll}
\hline Rank & $\begin{array}{l}1 \\
\text { (most important) }\end{array}$ & 2 & 3 & $\begin{array}{l}4 \\
\text { (least important) }\end{array}$ \\
\hline China & GE & Symptoms & Endoscopy & Questionnaire \\
Hong Kong & GE & Symptoms & Endoscopy & Questionnaire \\
Indonesia & Symptoms & Questionnaire & Endoscopy & GE \\
Japan & Symptoms & Endoscopy & Questionnaire & GE \\
Korea & Symptoms & GE & Questionnaire & Endoscopy \\
Philippines & Symptoms & Questionnaire & Endoscopy & GE \\
Singapore & GE & Endoscopy & Symptoms & Questionnaire \\
Thailand & Symptoms & Endoscopy & GE & Questionnaire
\end{tabular}

GP, gastroparesis; GE, gastric emptying.

and Philippines, and PDS was more prevalent than EPS in China, Singapore, and Thailand. The prevalence of EPS and PDS were almost equal in Japan. One-fourth of FD patients showed overlap between EPS and PDS in 7 countries except Korea (Fig. 2).

The percentage of respondents who always or often use upper endoscopy and Helicobacter pylori (H. pylori) test to diagnose FD was more than $60 \%$ in 8 countries (Fig. 3a, b). That of respondents who always or often use questionnaire on symptoms of FD to diagnose FD was more than 50\% in China, Indonesia, and Singapore (Fig. 3c).

\section{Gastroparesis}

The median percentage of patients who were diagnosed as GP among patients who visited the respondent's institution was $0.2,0.3,1.4,0.5,0.7,10.0,1.0$, or $1.5 \%$ in China, Hong Kong, Indonesia, Japan, Korea, Philippines, Singapore, and Thailand, respectively, showing significant differences between countries (Fig. 1). The most important factors in the diagnosis of GP were GP symptoms such as nausea or vomiting in Indonesia, Japan, Korea, Philippines, and Thailand and the GE tests in China, Hong Kong, and Singapore. Questionnaire on GP symptoms was thought to be the second important factor in the 
Fig. 3. a Distribution of frequencies (respondents used questionnaire on symptoms of FD to diagnose FD). $\mathbf{b}$ Distribution of frequencies (respondents used upper endoscopy to diagnose FD). c Distribution of frequencies (respondents used H. pylori infection to diagnose FD. FD, functional dyspepsia.

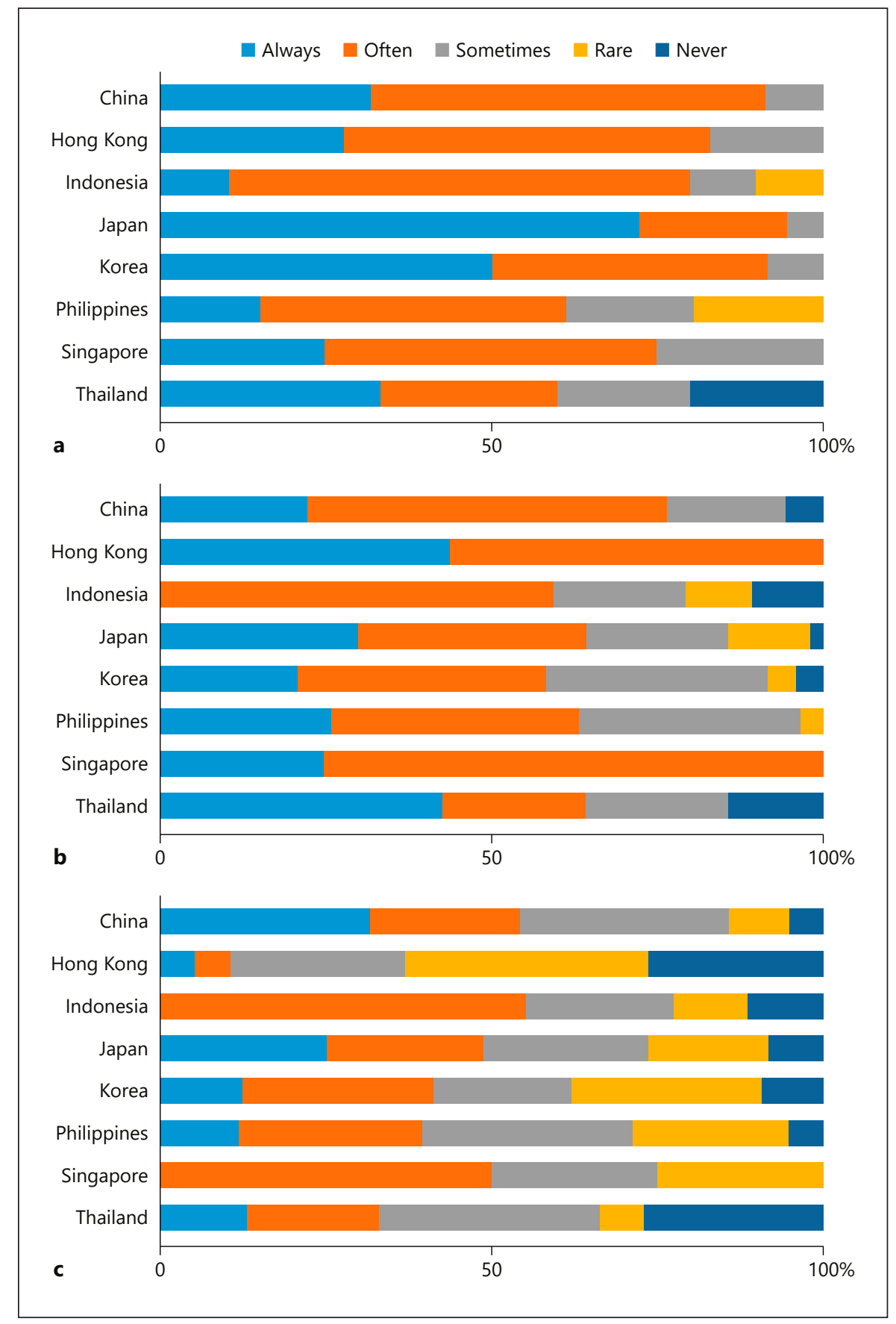

diagnosis of GP in Indonesia and Philippines as well as upper endoscopy in Japan, Singapore, and Thailand (Table 2).

Irritable Bowel Syndrome

The median percentage of patients who were diagnosed as IBS among patients who visited the respondent's institution was $5.0,10.0,1.6,3.2,7.7,12.3,9.4$, or $3.1 \%$ in
China, Hong Kong, Indonesia, Japan, Korea, Philippines, Singapore, and Thailand, respectively, showing significant differences between countries (Fig. 1). Figure 4 shows prevalence of subtypes of IBS using the Rome IV criteria in each country. Diarrhea predominant (IBS-D) was more prevalent than constipation predominant (IBSC) in China, Hong Kong, Indonesia, Korea, Japan, and Thailand, whereas IBS- $\mathrm{C}$ was more prevalent than IBS-D 


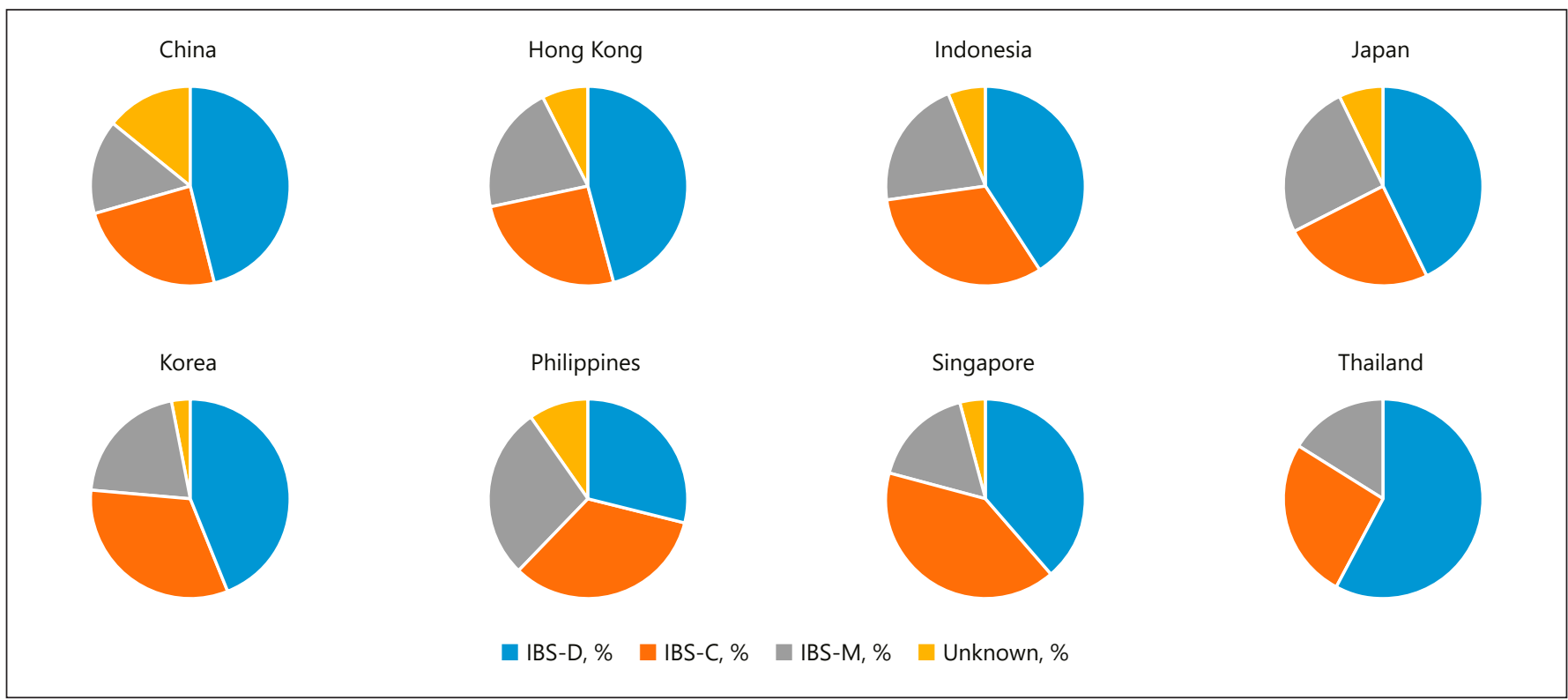

Fig. 4. The prevalence of subtypes of FD in each country. IBS-D, diarrhea predominant; IBS-C, constipation predominant; IBS-M, mixed bowel habit.

in Philippines and Singapore. Mixed bowel habits (IBSM) were found in 16-29\% (Fig. 4).

The percentage of respondents who always or often use colonoscopy to diagnose IBS was more than $60 \%$ in all 8 countries (Fig. 5a). That of respondents who always or often use questionnaire on symptoms of IBS to diagnose IBS was 71.4, 55.6, 58.3, 54.2, or 51.7\% in China, Indonesia, Japan, Korea, and Philippines, respectively (Fig. 5b). In contrast, the percentage of respondents who rarely or never use serum celiac-specific antibody to diagnose IBS was more than 90\% in Hong Kong, Indonesia, Japan, Korea, and Thailand (Fig. 5c).

\section{Chronic Constipation}

The median percentage of patients who were diagnosed as CC among patients who visited the respondent's institution was $5.0,2.8,2.0,5.9,6.1,16.7,3.0$, or $8.0 \%$ in China, Hong Kong, Indonesia, Japan, Korea, Philippines, Singapore, and Thailand, respectively, showing significant differences between countries (Fig. 1).

The percentage of respondents who always or often use colonoscopy to diagnose CC was more than $70 \%$ in all 8 countries (Fig. 6a). The percentage of respondents who rarely or never use colonic transit time tests to diagnose CC was more than $60 \%$ in China, Hong Kong, Indonesia, Japan, Philippines, and Thailand (Fig. 6b).

\section{Gastrointestinal Motility Testing}

\section{GE Tests}

GE tests were commonly used in clinical setting of Korea and Singapore. They were used in clinical setting or research only in half of institutions of Thailand. GE tests were not performed in more than $60 \%$ of institutions in other 5 countries (Table 3). Scintigraphy was used the most to measure GE in Hong Kong, Japan, Korea, Philippines, Singapore, and Thailand, whereas ${ }^{13} \mathrm{C}$ breath test was used the most in China (Table 4).

\section{Colonic Transit Time Tests}

Colonic transit time tests were commonly used in clinical setting in Korea and Singapore. They were used in clinical setting or research only in almost half of institutions of China. Colonic transit time tests were not performed in $66.7-100 \%$ institutions in other 5 countries (Table 5). Radiopaque marker method was used the most to measure colonic transit time in 7 countries except Indonesia (Table 6).

\section{Discussion}

FD is defined as a condition which chronically presents bothersome symptoms centered at the upper abdomen, such as postprandial fullness, early satiation, epigas- 
Fig. 5. a Distribution of frequencies (respondents used questionnaire on symptoms of IBS for diagnosis of IBS. b Distribution of frequencies (respondents used colonoscopy to diagnose IBS). c Distribution of frequencies (respondents used serum celiac-specific antibody to diagnose IBS). IBS, irritable bowel syndrome.

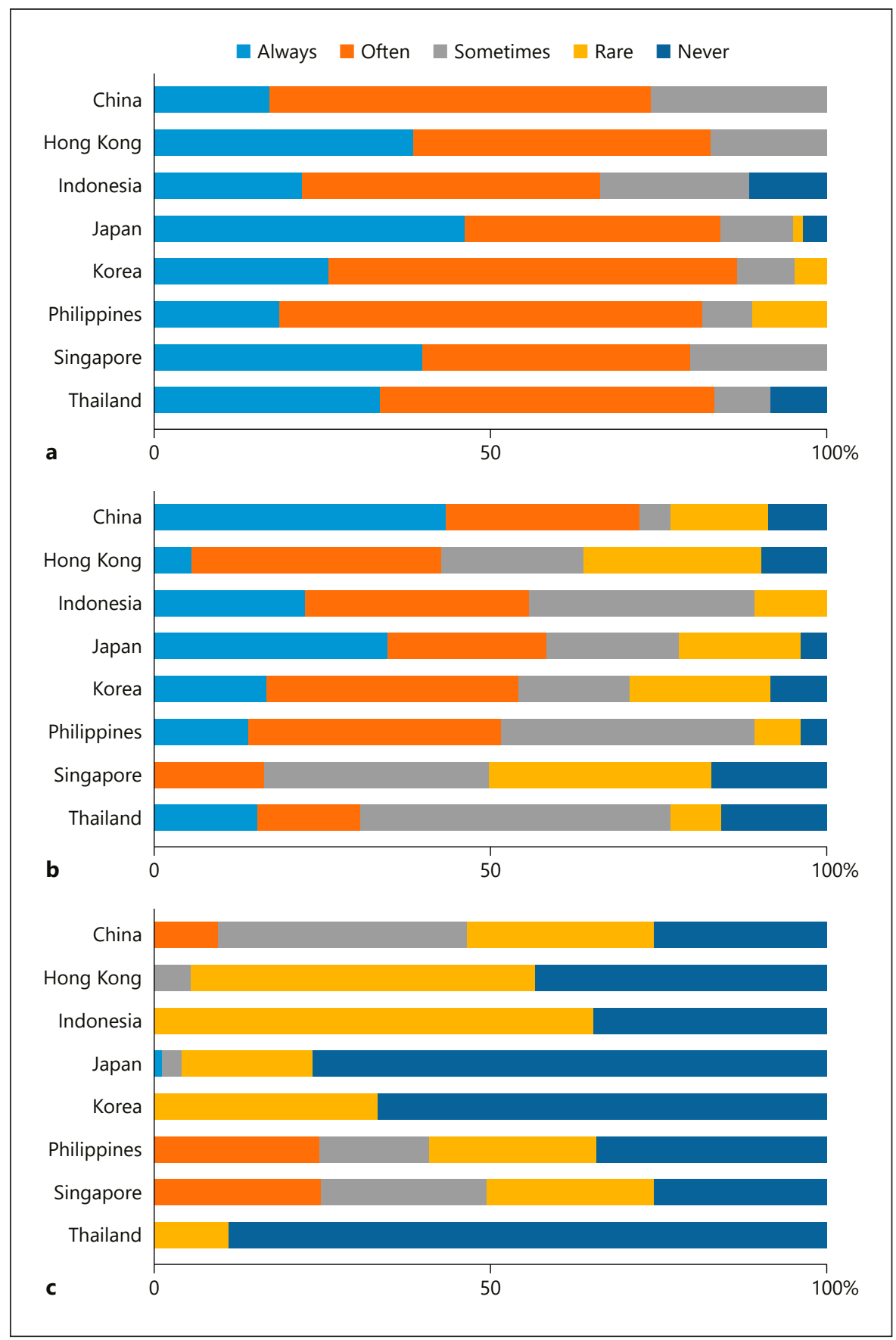

tric pain, and epigastric burning without any structural disease that is likely to explain the symptoms [2]. FD is a very common disease and several large-scale studies [10, 11] reported that its prevalence is $8-30 \%$ worldwide. In this survey, the median percentage of FD patients who visited the institutions in each country ranged from 3.3 to $20 \%$. The prevalence of FD could differ depending on the community base, hospital setting, or whether subjects were general population or outpatients. The prevalence of dyspepsia in Japan was estimated to be $21.9 \%$, and the percentage of patients who visited a medical institute was only $5.7 \%$ of Japanese population [12]. In other words, only one-fourth of dyspeptic subjects visited a medical institute. These data support our results.

In the Rome IV criteria, FD patients are categorized into 3 subtypes: EPS, PDS, and the overlap of EPS and 
Fig. 6. a Distribution of frequencies (respondents used colonoscopy to diagnose CC). b Distribution of frequencies (respondents used colonic transit time tests to diagnose CC). CC, chronic constipation.

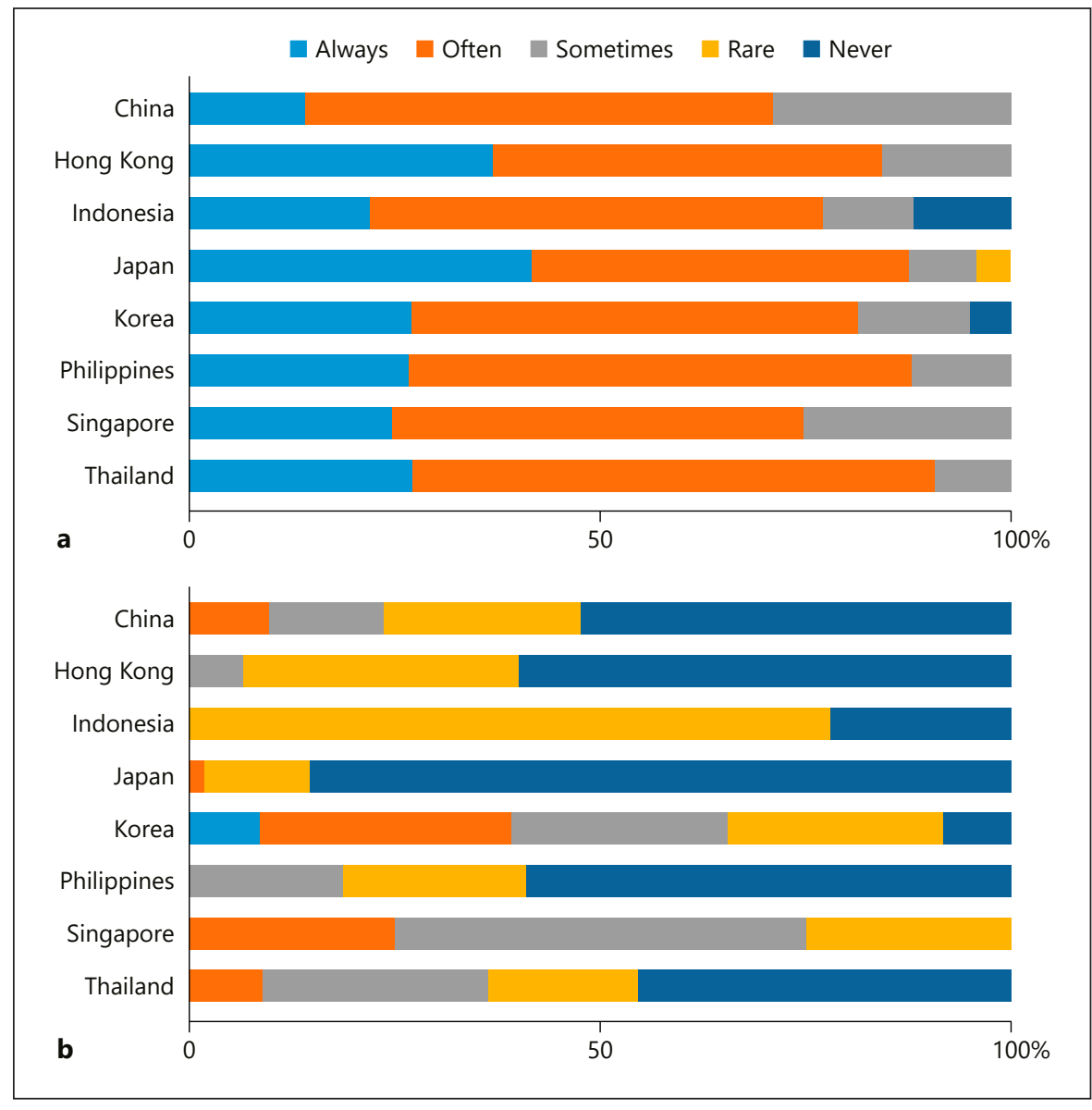

Table 3. Number of institutes where respondents performed GE test

\begin{tabular}{lllr}
\hline Country & $\begin{array}{l}\text { Yes } \\
\text { (clinical setting) }\end{array}$ & $\begin{array}{l}\text { Yes } \\
\text { (research only) }\end{array}$ & $\mathrm{No}^{*}$ \\
\hline China & 5 & 2 & 12 \\
Hong Kong & 2 & 4 & 13 \\
Indonesia & 1 & 1 & 7 \\
Japan & 2 & 4 & 66 \\
Korea & 18 & 3 & 3 \\
Philippines & 3 & 3 & 20 \\
Singapore & 3 & 1 & 0 \\
Thailand & 3 & 2 & 5 \\
\hline
\end{tabular}

GE, gastric emptying. * Significant differences between countries $\left(p<0.001, \chi^{2}\right.$ test $)$.

PDS [2]. Regarding the prevalence of subtypes of FD, Oshima and Miwa [13] have confirmed in 6 reports that PDS was more prevalent than EPS, defined by the Rome
III criteria in both Europe and Asia. Aziz et al. [11] have demonstrated that the proportions of subgroups are $18 \%$ in EPS, $61 \%$ in PDS, and $21 \%$ in overlap in the USA, Canada, and UK using the Rome IV criteria. However, EPS was more prevalent than PDS in 8 countries including Hong Kong, Indonesia, Korea, and Philippines in this survey. The prevalence of EPS and PDS was almost equal in Japan. There might be epidemiological differences in FD between Western countries and Asian countries.

To diagnose FD, upper endoscopy and $H$. pylori test were always or often used in more than half of institutions of 8 countries. A diagnosis of FD is based on both patients' self-reported symptoms and exclusion of organic disease. Upper endoscopy is recommended to exclude organic disease because it is impossible to distinguish FD and organic dyspepsia only using subjective symptoms.

The relationship between $H$. pylori infection and FD remains controversial. The USA, Korea, Thailand, and Japanese clinical practice guidelines for the management
80
Kamiya et al. 
Table 4. Number of institutes where respondents performed tests to evaluate GE

\begin{tabular}{llllll}
\hline Country & Scintigraphy & $\begin{array}{l}{ }^{13} \mathrm{C} \text { breath } \\
\text { test }\end{array}$ & $\begin{array}{l}\text { Radiopaque } \\
\text { markers }\end{array}$ & $\begin{array}{l}\text { Ultra- } \\
\text { sonography }\end{array}$ & $\begin{array}{l}\text { Wireless } \\
\text { capsule }\end{array}$ \\
\hline China & 3 & 4 & 2 & 0 & 2 \\
Hong Kong & 6 & 0 & 1 & 0 & 0 \\
Indonesia & 0 & 0 & 1 & 1 & 0 \\
Japan & 2 & 1 & 2 & 1 & 2 \\
Korea & 19 & 1 & 0 & 0 & 0 \\
Philippines & 3 & 2 & 0 & 0 & 0 \\
Singapore & 2 & 1 & 1 & 0 & 0 \\
Thailand & 4 & 1 & 1 & & 2 \\
\hline
\end{tabular}

GE, gastric emptying.

Table 5. Number of institutes where respondents performed colonic transit time test

\begin{tabular}{llll}
\hline Country & $\begin{array}{l}\text { Yes } \\
\text { (clinical setting) }\end{array}$ & $\begin{array}{l}\text { Yes } \\
\text { (research only) }\end{array}$ & No* $^{*}$ \\
\hline China & 8 & 1 & 10 \\
Hong Kong & 1 & 3 & 14 \\
Indonesia & 0 & 0 & 9 \\
Japan & 0 & 3 & 69 \\
Korea & 17 & 2 & 3 \\
Philippines & 2 & 3 & 17 \\
Singapore & 3 & 1 & 0 \\
Thailand & 3 & 0 & 6 \\
\hline
\end{tabular}

* Significant differences between countries $\left(p<0.001, \chi^{2}\right.$ test $)$.

of FD recommend to assess the $H$. pylori infection and eradicate $H$. pylori in positive FD patients. Patients who remain symptom free 6-12 months after eradication are considered to be the " $H$. pylori-associated FD" cases [1416]. A recent report indicated that approximately $60 \%$ of H. pylori-associated dyspepsia patients improved at 1 month after eradication. The questionnaire at less than 3 month after eradication might help to diagnose $H$. pyloriassociated dyspepsia [17].

GP is defined as a syndrome in which GE is objectively delayed without mechanical obstruction showing cardinal symptoms including early satiety, postprandial fullness, nausea, vomiting, bloating, and upper abdominal pain $[18,19]$. GP can be categorized into some subsets based on its etiology. Soykan et al. [20] reported that diabetic (29\%), postsurgical (13\%), and idiopathic (36\%) origins, and the remaining cases represented Parkinson's
Table 6. Number of institutes which performed tests to evaluate colonic transit time

\begin{tabular}{llll}
\hline Country & Scintigraphy & $\begin{array}{l}\text { Radiopaque } \\
\text { markers }\end{array}$ & $\begin{array}{l}\text { Wireless } \\
\text { capsule }\end{array}$ \\
\hline China & 2 & 8 & 3 \\
Hong Kong & 0 & 4 & 0 \\
Indonesia & 0 & 0 & 0 \\
Japan & 0 & 3 & 0 \\
Korea & 0 & 18 & 1 \\
Philippines & 1 & 2 & 2 \\
Singapore & 0 & 3 & 0 \\
Thailand & 0 & 3 & 0 \\
\hline
\end{tabular}

disease and collagen-vascular disorders. GP is a relatively common disease in Western countries, and the 10-year incidence of GP has been reported to be $5.2 \%$ in type 1 diabetes, $1 \%$ in type 2 diabetes, and $0.2 \%$ in nondiabetic controls in a US community [21]. In contrast, the median percentage of GP patients who visited the respondent's institution was from 0.2 to $1.5 \%$ in 7 countries except Philippines.

GP is diagnosed using both cardinal symptoms and GE test. Symptoms of GP are often evaluated using the Gastroparesis Cardinal Symptom Index (GCSI), a specific questionnaire for GP. The most important factor in the diagnosis of GP was the GE test in China, Hong Kong, and Singapore, whereas it was the least important in Indonesia, Japan, and Philippines. Furthermore, the least important factor was the questionnaire in China, Hong Kong, Singapore, and Thailand. The prevalence 
of GP in Asian countries is probably lower than Western countries, or GP may have received relatively little attention in Asian countries. Recent practice survey of GP by Asian Neurogastroenterology and Motility Association reported that the reason why GP can be challenging to diagnose might be due to the lack of instrument [22].

IBS is a representative FGID characterized by chronic or recurrent abdominal pain associated with abnormal defecation or a change in bowel habits [3]. The worldwide prevalence of IBS is $11.2 \%$ based on a meta-analysis of 80 studies involving 260,960 subjects [23]. That of IBS ranged from 10 to $15 \%$ in a systematic review of IBS in North America. However, the median percentage of IBS patients who visited the respondent's institutions was from 1.6 to $12.3 \%$ and less than $10 \%$ in 6 countries in our survey. Miwa [24] reported the prevalence of IBS in Japan was $13.1 \%$. Another paper demonstrated that the prevalence of IBS who visited a general hospital in Japan was $2.4 \%$ [25]. Many IBS patients may have not visited medical institutions.

IBS patients are categorized into 4 subgroups in the Rome IV: IBS-D, IBS-C, IBS-M, and unclassified (IBS-U) [3]. A review of 8 studies showed that IBS-D is more prevalent than IBS-C. No difference was observed in the prevalence of subtypes of IBS between Western countries and Asia.

To diagnose IBS, colonoscopy and questionnaire are always or often used in more than $50 \%$ of institutions in 8 countries and 7 countries, respectively. Both colonoscopy and questionnaire are recommended to diagnose IBS in Japanese clinical guideline [26]. Colonoscopy has a diagnostic value to exclude organic disease. Questionnaires are also useful in the diagnosis of IBS.

In contrast, serum celiac-specific antibody are not examined in most institutions in Asian countries. Celiac disease is a chronic immune-mediated disease induced by dietary gluten in genetically predisposed individuals [27, 28]. Celiac disease can present many IBS-like gastrointestinal symptoms including diarrhea, bloating, and abdominal pain. The prevalence of celiac disease is $\sim 1.0 \%$ of the population in many regions of the world [28], and it significantly increased in Western countries. However, eastern Asia shows low prevalence rate of celiac disease probably due to both a lack of gluten predisposition and a low consumption of wheat.

$\mathrm{CC}$ is a very common disease. Its prevalence in general population is approximately $14 \%$ based on a large meta-analysis of 45 population-based survey, comprising 26,040 adults, and more than $20 \%$ in elderly $\geq 70$ years old [29-31]. However, the median percentage of CC patients who visited respondent's institutions was from 2.0 to $16.7 \%$ and less than $10 \%$ in 7 countries. Most of CC patients probably did not visit medical institutions.

To diagnose CC, colonoscopy is always or often used in more than $50 \%$ of institutions in 8 countries. CC is either primary or secondary (attributed to another disease such as colon cancer, diabetes mellitus, or Parkinson's disease). Primary CC consists of functional constipation and IBS-C. Colonoscopy is essential to exclude organic disease including colon cancer.

The frequency of gastrointestinal motility testing including GE and colonic transit time varied among Asian countries. There are many gastrointestinal motility or function testing. Most of them are not widely used in clinical setting in Asia except Korea and Singapore. GE tests are needed to diagnose GP, and disturbance of GE is involved in pathogenesis of FD. Many studies indicate that GE is significantly delayed in almost $20-35 \%$ of FD patients $[32,33]$. The current gold standard in diagnostic assessment of GP is GE scintigraphy. However, the test is expensive, extensive, and unavailable in most hospitals even in Western countries. Other methods to measure GE are breath test or wireless motility capsule. ${ }^{13} \mathrm{C}$ breath test is a reliable, noninvasive, and simple test to evaluate GE. Scintigraphy and ${ }^{13} \mathrm{C}$ breath test are reported to give similar results for GE [34].

$\mathrm{CC}$ is classified into 3 categories based on assessments of colonic transit and anorectal function: normal transit constipation, slow transit constipation, and pelvic flow dysfunction [35]. Recently, Bharucha and Lacy [36] showed a treatment algorithm for CC. Colonic transit time should be assessed when the symptoms do not improve after treatment of secretagogue or prokinetic agents. The radiopaque marker method is an accurate and widely used technique to evaluate colonic transit time [37]. In addition, colonic transit time has been reported to be faster in Asian populations than in the West $[38,39]$. Gastrointestinal motility tests including ${ }^{13} \mathrm{C}$ breath test and radiopaque marker method are desired in all Asian countries.

In conclusion, this questionnaire survey revealed epidemiology of FGIDs and current status of gastrointestinal motility testing in various Asian countries. The frequency of FD, GP, IBS, and CC varied significantly among Asian countries. In addition, cooperation to develop skills to use gastrointestinal motility testing more effectively in FGIDs is necessary in all Asian countries.
Kamiya et al. 


\section{Appendix}

Please check the appropriate box or specify your answer in the blank spaces. In principle, the definition of each disease is according to Rome IV criteria. However, it depends on the situation of each country respectively.

\section{General}

1. What is your country of residence?

\begin{tabular}{|l|l|}
\hline$\checkmark$ & \\
\hline & China \\
\hline & Hong Kong \\
\hline & Indonesia \\
\hline & Japan \\
\hline & Korea \\
\hline & Philippines \\
\hline & Singapore \\
\hline & Thailand \\
\hline & Other \\
\hline
\end{tabular}

2. What is your specialty?

\begin{tabular}{|l|l|}
\hline$\checkmark$ & \\
\hline & gastroenterology \\
\hline & gastrointestinal surgery \\
\hline & general physician \\
\hline & Other $\quad$ \\
\hline
\end{tabular}

3. How many patients do visit your department of the hospital per month on average?

patients /month

4. How many patients do undergo upper endoscopy in your department per month on average?

patients /month

5. How many patients do undergo colonoscopy in your department per month on average?

\begin{tabular}{|l|l|}
\hline & patients /month \\
\hline
\end{tabular}

\section{Functional dyspepsia (FD)}

6. How many functional dyspepsia (FD) patients do visit your department of the hospital per month on average? patients /month

7. What is the percentage of subgroups in FD patients who are treated in your department?

\begin{tabular}{|l|l|l|}
\hline epigastric pain syndrome & & $\%$ \\
\hline postprandial distress syndrome & & $\%$ \\
\hline overlap & & $\%$ \\
\hline
\end{tabular}


8. How often do you perform the following examinations to diagnose and/or to make the differential diagnosis of FD? a. questionnaire on symptoms of FD

\begin{tabular}{|l|l|l|l|l|l|l|}
\hline & always \\
\hline & often
\end{tabular}$\quad$\begin{tabular}{l|l|l|l|}
\hline & sometimes \\
$y$
\end{tabular}

b. barium upper gastrointestinal radiography

\begin{tabular}{|c|c|c|c|c|}
\hline always & often & sometimes & rarely & never \\
\hline \multicolumn{5}{|c|}{ c. upper endoscopy } \\
\hline always & often & sometimes & rarely & never \\
\hline
\end{tabular}

d. abdominal ultrasonography

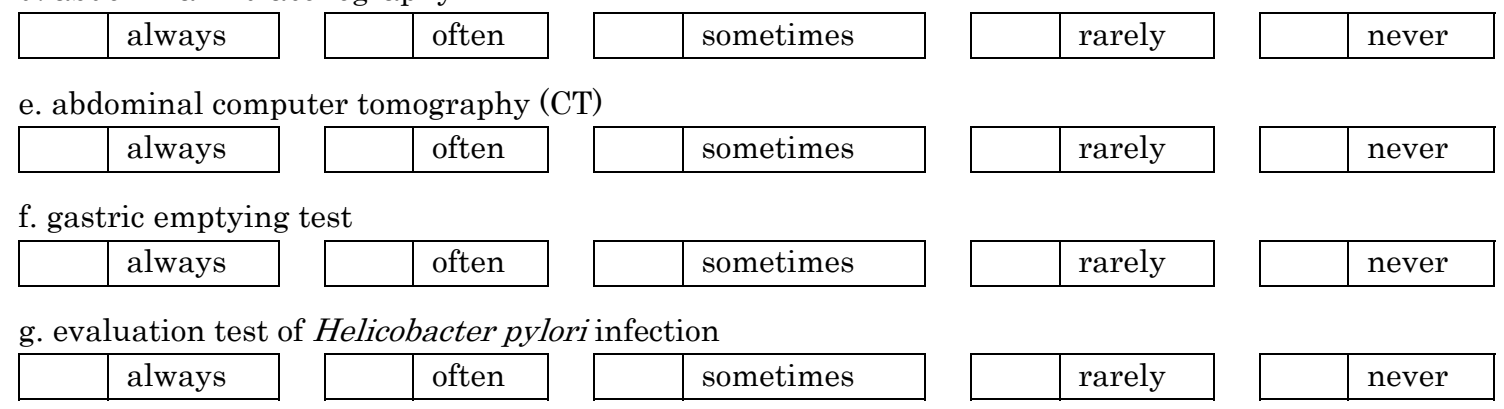

h. others

\begin{tabular}{|l|l|l|l|l|l|l|l|l|l|l|}
\hline \multicolumn{2}{|l|}{ always } & & often & & sometimes & & rarely & & never \\
\hline
\end{tabular}

\section{Gastroparesis}

9. How many gastroparesis patients do visit your department of the hospital per month on average?

\begin{tabular}{|l|l|}
\hline & patients /month \\
\hline
\end{tabular}

10. What is the percentage of the etiology in gastroparesis patients who are treated in your department?

\begin{tabular}{|l|l|l|}
\hline diabetes mellitus & $\%$ \\
\hline idiopathic & & $\%$ \\
\hline postsurgical & & $\%$ \\
\hline others & & $\%$ \\
\hline
\end{tabular}

11. What do you think is the most important for diagnosing Gastroparesis?

Number the items in order from 1 (most important) to 4 (least important).

\begin{tabular}{|l|l|}
\hline $1-4$ & \\
\hline & symptoms of vomiting, nausea, epigastric pain, early satiety and/or postprandial fullness \\
\hline & patient questionnaire on symptoms of Gastroparesis \\
\hline & upper endoscopy \\
\hline & gastric emptying test \\
\hline
\end{tabular}


Irritable bowel syndrome (IBS)

12. How many irritable bowel syndrome (IBS) patients do visit your department of the hospital per month on average?

\begin{tabular}{|l|l|}
\hline & patients /month \\
\hline
\end{tabular}

13. What is the percentage of subtypes in IBS patients who are treated in your department?

\begin{tabular}{|l|l|l|}
\hline diarrhea-predominant & & $\%$ \\
\hline constipation-predominant & & $\%$ \\
\hline mixed type & & $\%$ \\
\hline unknown & & $\%$ \\
\hline
\end{tabular}

14. How often do you perform the following examinations to diagnose and/or to make the differential diagnosis of IBS? a. questionnaire on symptoms of IBS

\begin{tabular}{|l|l|l|l|l|l|l|l|}
\hline & always \\
\hline & often \\
\hline
\end{tabular}

b. abdominal computer tomography (CT)

\begin{tabular}{|l|l|l|l|l|l|l|l|}
\hline & always \\
\hline & often \\
\hline
\end{tabular}

c. abdominal magnetic resonance imaging (MRI)

\begin{tabular}{|l|l|l|l|l|l|l|l|}
\hline & always \\
\hline & often & sometimes & rarely & never \\
\hline
\end{tabular}

d. colonoscopy

\begin{tabular}{|l|l|}
\hline always \\
\hline
\end{tabular}
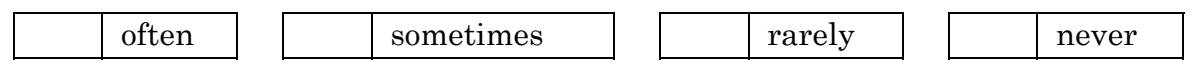

e. fecal occult blood test

\begin{tabular}{|l|l|l|}
\hline & always & often \\
\hline
\end{tabular}

\begin{tabular}{|l|l|}
\hline & sometimes \\
\hline
\end{tabular}

\begin{tabular}{|l|l|}
\hline & rarely \\
\hline
\end{tabular}

\begin{tabular}{|l|l|}
\hline & never \\
\hline
\end{tabular}

f. fecal bacterial culture

\begin{tabular}{|l|l|}
\hline & always \\
\hline
\end{tabular}

\begin{tabular}{|l|l|}
\hline & often \\
\hline
\end{tabular}

\begin{tabular}{|l|l|}
\hline & sometimes \\
\hline
\end{tabular}

\begin{tabular}{|l|l|}
\hline & rarely \\
\hline
\end{tabular}

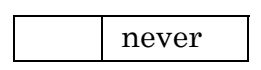

g. lactose tolerance test

\begin{tabular}{|l|l|}
\hline & always \\
\hline
\end{tabular}
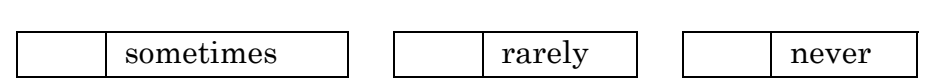

h. hydrogen breath test

\begin{tabular}{|c|c|c|c|c|}
\hline always & often & sometimes & rarely & never \\
\hline \multicolumn{5}{|c|}{ i. serologic tests for celiac disease } \\
\hline always & often & sometimes & rarely & never \\
\hline
\end{tabular}

j. others

\begin{tabular}{|l|l|l|l|l|l|l|l|l|l|l|}
\hline \multicolumn{1}{|l|}{ never } \\
\hline
\end{tabular}

\section{Chronic constipation}

15. How many chronic constipation patients do visit your department of the hospital per month on average? patients /month 
16. How often do you perform the following examinations to diagnose and/or to make the differential diagnosis of chronic constipation?

a. questionnaire on symptoms of chronic constipation

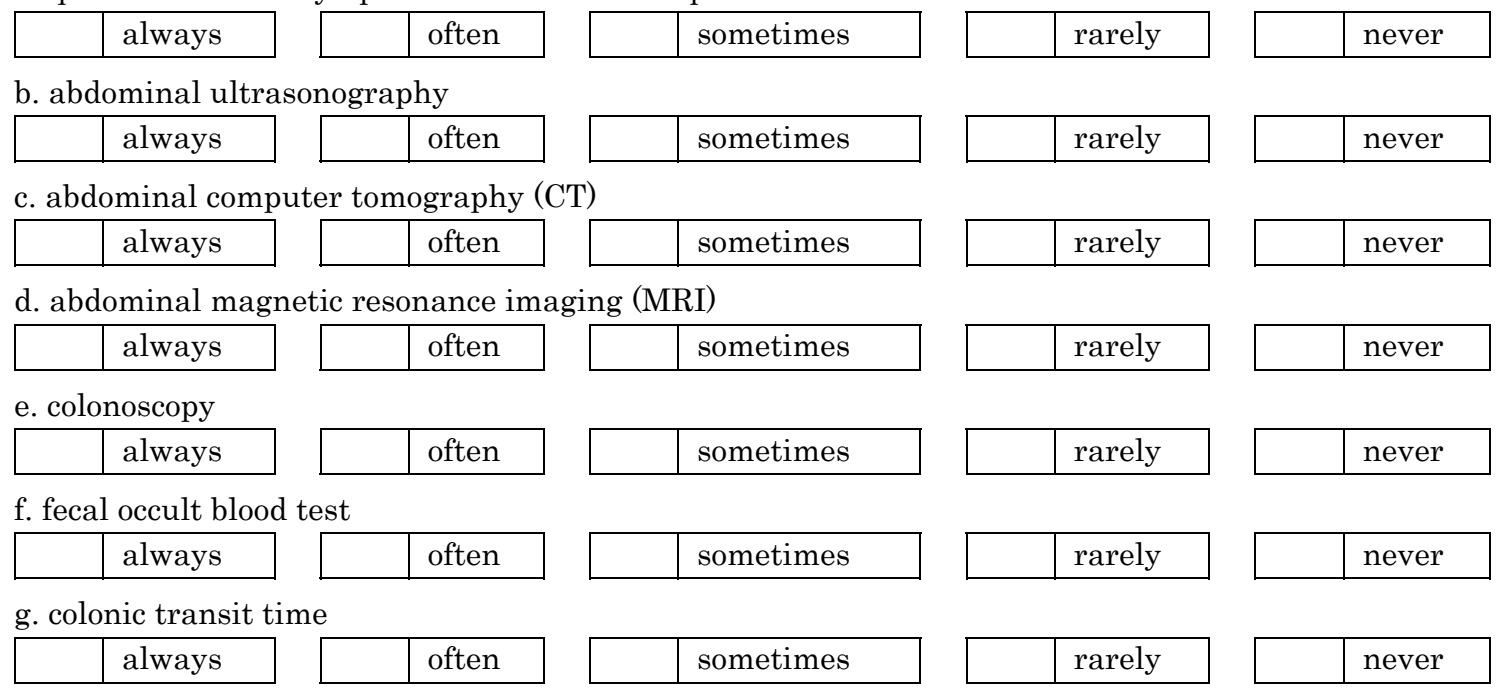

h. others

\begin{tabular}{|l|l|l|l|l|l|l|l|l|l|l|}
\hline \multicolumn{1}{|l|}{ always } \\
\hline
\end{tabular}

\section{Gastrointestinal motility testing}

17. Do you perform the gastric emptying test in your department?

\begin{tabular}{|l|l|}
\hline$\checkmark$ & \\
\hline & Yes (performed commonly in clinical setting) \\
\hline & Yes (performed for research) \\
\hline & No \\
\hline
\end{tabular}

18. If you answered Yes, which testing do you perform as the gastric emptying test?

\begin{tabular}{|l|l|}
\hline$\checkmark$ & \\
\hline & scintigraphy (radio-isotope technique) \\
\hline & ${ }^{13} \mathrm{C}$ breath test \\
\hline & real-time ultrasonography \\
\hline & radio-paque markers \\
\hline & wireless capsule or capsule endoscopy \\
\hline & others \\
\hline
\end{tabular}

19. How often do you perform those gastric emptying tests?

\begin{tabular}{|l|l|l|l|l|l|l|l|l|}
\hline & always \\
\hline & often \\
\hline
\end{tabular}

20. Do you perform the colonic transit time test in your department?

\begin{tabular}{|l|l|}
\hline$\checkmark$ & \\
\hline & Yes (performed commonly in clinical setting) \\
\hline & Yes (performed for research) \\
\hline & No \\
\hline
\end{tabular}


21. If you answered Yes, which testing do you perform as the colonic transit time test?

\begin{tabular}{|l|l|}
\hline$\checkmark$ & \\
\hline & scintigraphy (radio-isotope technique) \\
\hline & radiopaque markers \\
\hline & wireless capsule or capsule endoscopy \\
\hline & others : \\
\hline
\end{tabular}

22. How often do you perform those colonic transit time tests?

\begin{tabular}{|l|l|l|l|l|l|l|l|l|}
\hline & always \\
\hline & often
\end{tabular}$\quad$\begin{tabular}{|l|l|l|l|l|}
\hline & sometimes \\
never
\end{tabular}

23. How often do you perform the following gastrointestinal function testing to diagnose and/or to treat functional gastrointestinal disorders?

a. $\mathrm{pH}$ monitoring and/or impedance

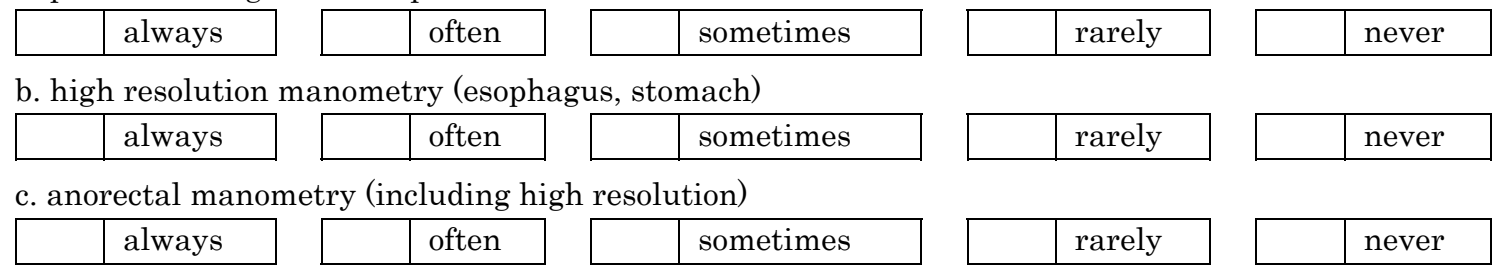

d. small intestinal or colonic manometry (including high resolution)

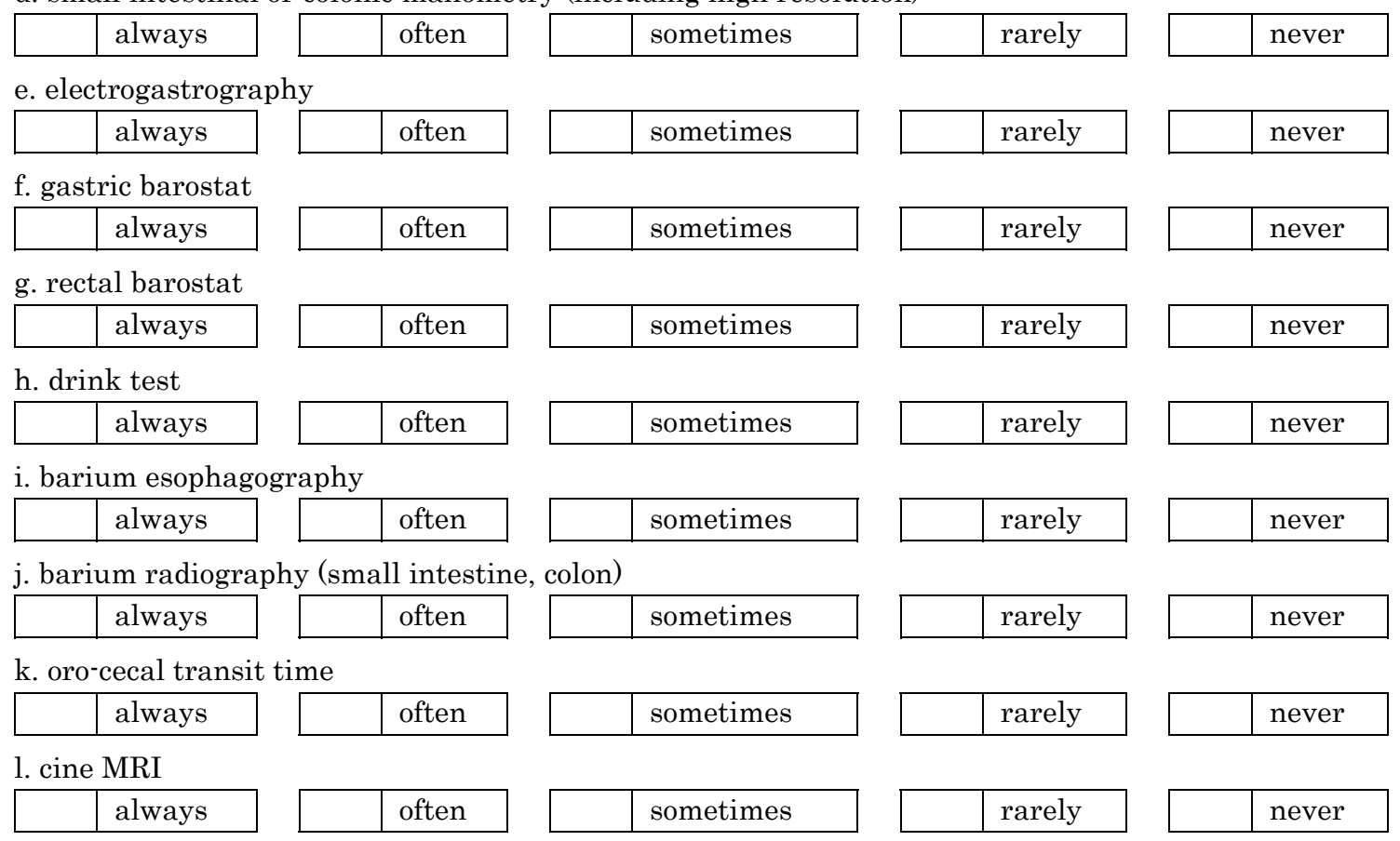

m. others

\begin{tabular}{|c|c|c|c|c|}
\hline alwavs & often & sometimes & rarely & never \\
\hline
\end{tabular}

n. others

\begin{tabular}{|l|l|l|l|l|l|l|l|l|l|l|}
\hline \multicolumn{1}{|c|}{} & always \\
\hline & & often & & & sometimes & & rarely & & & never \\
\hline
\end{tabular}

o. others

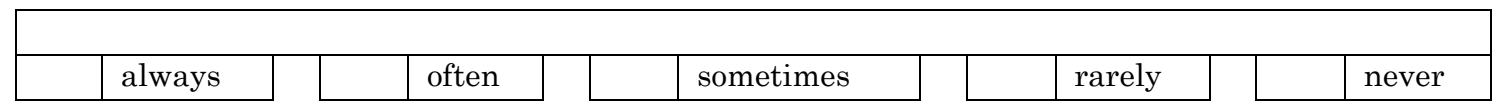

Situation of FGIDs and Gastrointestinal Motility Test 


\section{Acknowledgements}

The authors thank all doctors who participated in this survey and also the office personnel of the International Gastrointestinal Consensus Symposium for their secretarial work.

\section{Statement of Ethics}

This survey is questionnaire based not to patients but to each institution, and personal information is not handled. This kind of study does not require the approval of ethical review board according to the Japanese "guidelines for medical and health research involving human subjects" by Japanese Ministry of Health, Labor, and Welfare.

\section{Funding Sources}

The authors have no funding sources.

\section{Author Contributions}

Dr. Takeshi Kamiya designed the study, collected and analyzed the questionnaire, and drafted the manuscript. Dr. Satoshi Osaga performed the statistical analysis. Drs. Eiji Kubota, Shin Fukudo, Satoshi Motoya, Kazunari Murakami, Akihito Nagahara, Akiko Shiotani, Mitsushige Sugimoto, Hidekazu Suzuki, Toshio Watanabe, Satoru Yamaguchi, Francis K.L. Chan, Ki-Baik Hahm, Kwong Ming Fock, and Qi Zhu reviewed and aggregated the questionnaire.

\section{Conflict of Interest Statement}

The authors have no conflicts of interests to declare.

\section{References}

1 Drossman DA. Functional gastrointestinal disorders: history, pathophysiology, clinical features, and Rome IV. Gastroenterology. 2016 May;150(6):1262-79.

2 Stanghellini V, Chan FK, Hasler WL, Malagelada JR, Suzuki H, Tack J, et al. Gastroduodenal disorders. Gastroenterology. 2016 May; 150(6):1380-92.

3 Lacy BE, Mearin F, Chang L, Chey WD, Lembo AJ, Simren M, et al. Bowel disorders. Gastroenterology. 2016 May;150(6):1393-407.

4 Boeckastaens G, Camileri M, Sifrim D, Houghton LA, Elsenbuch S, Lindberg G, et al. Fundamentals of neurogastroenterology: physiology/motility-sessation. Gastroenterology. 2016 May;150(6):1292-304.

5 Tack J, Bisschops R, Sarnelli G. Pathophysiology and treatment of functional dyspepsia. Gastroenterology. 2004 Oct;127(4):1239-55.

6 Wilder-Smith CH. The balancing act: endogenous modulation of pain in functional gastrointestinal disorders. Gut. 2011 Nov;60(11) 1589-99.

7 Barbara G, Feinle-Bisset C, Ghoshal UC, Quigley EM, Santos J, Vanner S, et al. The intestinal microenvironment and functional gastrointestinal disorders. Gastroenterology. 2016 May;150(6):1305-18.

8 Simren M, Barbara G, Fint HJ, Spiegel BMR, Spiller RC, Vanner S, et al. Intestinal microbiota in functional bowel disorders: a Rome foundation report. Gut. 2013 Jan;62(1):15976.

9 Tillisch K, Labus JS. Advances in imaging the brain-gut axis: functional gastrointestinal disorders. Gastroenterology. 2011 Feb;140(2): $407-\mathrm{e} 1$.
10 Mahadeva S, Goh KL. Epidemiology of functional dyspepsia: a global perspective. World J Gastroenterol. 2006 May;12(17):2661-6.

11 Aziz I, Palsson OS, Törnblom H, Sperber AD, Whitehead WE, Simrén M. Epidemiology, clinical characteristics, and associations for symptom-based Rome IV functional dyspepsia in adults in the USA, Canada, and the UK: a crosssectional population-based study. Lancet Gastroenterol Hepatol. 2018 Apr;3(4):252-62.

12 Oshima T, Miwa H. [Functional gastrointestinal disorders (FGID): progress in diagnosis and treatment. Topic I. Basic knowledge of functional gastrointestinal disorders (FGID): 1. Epidemiology of FGID]. Nihon Naika Gakkai Zasshi. 2013 Jan;102(1):4-10.

13 Oshima T, Miwa H. Epidemiology of functional gastrointestinal disorders in Japan and in the world. J Neurogastroenterol Motil. $2015 \mathrm{Jul} ; 21(3): 320-9$.

14 Miwa H, Kusano M, Arisawa T, Oshima T, Kato M, Joh T, et al. Evidence-based clinical practice guidelines for functional dyspepsia. J Gastroenterol. 2015 Feb;50(2):125-39.

$15 \mathrm{Oh} \mathrm{JH}$, Kwon JG, Jung HK, Tae CH, Song KH, Kang SJ, et al. Clinical practice guidelines for functional dyspepsia in Korea. J Neurogastroenterol Motil. 2020 Jan;26(1):29-50.

16 Pittayanon R, Leelakusolvong S, Vilaichone RK, Rojborwonwitaya J, Treeprasertsuk S, Mairiang P, et al. Thailand dyspepsia guidelines. J Neurogastroenterol Motil. 2018 Jan; 25(1):15-26.

17 Tsuda M, Kato M, Ono S, Matsuda K, Miyamoto S, Abiko S, et al. Changes of dyspeptic symptom after successful eradication in Helicobacter pylori-associated dyspepsia. Digestion. 2020 Apr;101(2):165-73.
18 Camilleri M, Parkman HP, Shafi MA, Abell TL, Gerson L. Clinical Guideline: management of Gastroparesis. Am J Gastroenterol. 2013 Jan; 108(1):18-38.

19 Camilleri M, Grover M, Farrugia G. What are the important subsets of gastroparesis? Neurogastroenterol Motil. 2012;24(7):597-603.

20 Soykan I, Sivri B, Sarosiek I, Kiernan B, McCallum RW. Demography, clinical characteristics, psychological and abuse profiles, treatment, and long-term follow-up of patients with gastroparesis. Dig Dis Sci. 1998 Nov; 43(11):2398-404.

21 Choung RS, Locke GR, Schleck CD, Zinsmeister AR, Melton LJ 3rd, Talley NJ. Risk of gastroparesis in subjects with type 1 and $2 \mathrm{di}-$ abetes in the general population. Am J Gastroenterol. 2012 Jan;107(1):82-8.

22 Oshima T, Siah KTH, Kim YS, Patcharatrakul T, Chen CL, Mahadeva S, et al. Knowledge, attitude, and practice survey of gastroparesis in Asia by Asian Neurogastroenterology and Motility Association. J Neurogastroenterol Motil. 2020.

23 Lovell RM, Ford AC. Global prevalence of and risk factors for irritable bowel syndrome: a meta-analysis. Clin Gastroenterol Hepatol. 2012 Jul;10(7):712-e4.

24 Miwa H. Prevalence of irritable bowel syndrome in Japan: internet survey using Rome III criteria. Patient Prefer Adherence. 2008 Feb;2(2):143-7.

Kamiya et al. 
25 Nakajima S, Takahashi K, Sato J, Fukuda M, Yamamoto K, Inoue T, et al. Spectra of functional gastrointestinal disorders diagnosed by Rome III integrative questionnaire in a Japanese outpatient office and the impact of overlapping. J Gastroenterol Hepatol. 2010 May; 25(Suppl 1):S138-43.

26 Fukudo S, Kaneko H, Akiho H, Inamori M, Endo Y, Okumura T, et al. Evidence-based clinical practice guidelines for irritable bowel syndrome. J Gastroenterol. 2015 Jan;50(1): 11-30.

27 Rubio-Tapia A, Hill ID, Kelly CP, Calderwood AH, Murray JA. AGA clinical guideline: diagnosis and management of Celiac disease. Am J Gastroenterol. 2013 May;108(5):65676.

28 Kelly CP, Bai JC, Liu E, Leffler DA. Advances in diagnosis and management of Celiac disease. Gastroenterology. 2015 May; 148(6): 1175-86.

29 Aziz I, Whitehead WE, Palsson OS, Törnblom H, Simrén M. An approach to the diagnosis and management of Rome IV function- al disorders of chronic constipation. Expert Rev Gastroenterol Hepatol. 2020 Jan;14(1): 39-46.

30 Suares NC, Ford AC. Prevalence of, and risk factors for, chronic idiopathic constipation in the community: systematic review and metaanalysis. Am J Gastroenterol. 2011 Sep; 106(9):1582-92.

31 Choung RS, Locke GR, Schleck CD, Zinsmeister AR, Talley NJ. Cumulative incidence of chronic constipation: a population-based study 1988-2003. Aliment Pharmacol Ther. 2007 Dec;26(11-12):1521-8.

32 Sarneli G, Caenepeel P, Geypens B, Janssens J, Tack J. Symptoms associated with impaired gastric emptying of solids and liquids in functional dyspepsia. Am J Gastrioenterol. 2003 Apr;98(4):783-8.

33 Stanghellini V, Tack J. Gastroparesis: separate entity or just a part of dyspepsia. Gut. 2014 Dec;63(12):1972-8.

34 Ghoos YF, Maes BD, Geypens BJ, Mys G, Hiele MI, Rutgeerts PJ, et al. Measurement of gastric emptying rate of solids by means of a carbon-labeled octanoic acid breath test. Gastroenterology. 1993 Jun;104(6):1640-7.

35 Tack J, Müller-Lissner S, Stanghellini V, Boeckxstaens G, Kamm MA, Simren M, et al. Diagnosis and treatment of chronic constipation: a European perspective. Neurogastroenterol Motil. 2011 Aug;23(8):697-710.

36 Bharucha AE, Lacy BE. Mechanisms, evaluation, and management of chronic constipation. Gastroenterology. 2020 Apr; 158(5): 1232-e3.

37 Bharucha AE, Anderson B, Bouchoucha M. More movement with evaluating colonic transit in humans. Neurogastroenterol Motil. 2019 Feb;31(2):e13541.

38 Gwee KA, Bak YT, Ghoshal UC, Gonlachanvit S, Lee OY, Fock KM, et al. Asian consensus on irritable bowel syndrome. J Gastroenterol Hepatol. 2019 Jul;25(7):1189-205.

39 Chan YK, Kwan AC, Yuen H, Yeung YW, Lai $\mathrm{KC}, \mathrm{Wu}$ J, et al. Normal colon transit time in healthy Chinese adults in Hong Kong. J Gastroenterol Hepatol. 2004 Nov; 19(11):1270-5. 